\title{
Considerações sobre políticas de requalificação das Zeis com participação dos habitantes: limites e desafios para as áreas metropolitanas no Brasil
}

\author{
Reflections on policies to requalify the Zeis \\ with inhabitants' participation: limits \\ and challenges to metropolitan areas in Brazil
}

Elena Tarsi

\section{Resumo}

A segregação é um fenômeno estrutural da formação da cidade brasileira que depende de razões históricas e dinâmicas econômicas globais. A gestão dos assentamentos informais das metrópoles representa um dos maiores desafios da contemporaneidade. Depois de apresentar algumas análises críticas sobre o processo de formação da cidade informal no Brasil, o artigo descreve os resultados da elaboração do Plano de Bairro para Nova Constituinte na cidade de Salvador da Bahia. Este programa-piloto tinha o objetivo de contribuir ao processo experimental de determinação de políticas públicas para a gestão e requalificação das ZEIS: as considerações sobre limites e desafios são interessantes para toda América Latina.

Palavras-chave: assentamentos informais; planejamento participativo; ZEIS; Brasil.

\begin{abstract}
Segregation is a structural problem of the formation of Brazilian cities that depends on historical reasons and global economic dynamics. The management of informal settlements is one of the biggest challenges facing the contemporary metropolis. After presenting some critical analyses about the production of the informal city in Brazil, the article describes the results of the preparation of the Plan for the Neighbourhood of Nova Constituinte, in the city of Salvador, State of Bahia. This pilot program aimed to contribute to the experimental process of determination of public policies for the management and requalification of the Zeis (areas delimited in a city for the settlement of low-income population): the reflections on limits and challenges are interesting to Latin America as a whole.
\end{abstract}

Keywords: informal settlements; participatory planning; Zeis; Brazil. 


\section{Introdução}

Desde a primeira metade do século passado, o acelerado processo de urbanização das grandes e médias cidades do Brasil gerou um crescimento descontrolado dos assentamentos informais, cuja gestão representa um dos maiores desafios da sociedade contemporânea: estas áreas somam o degrado do ambiente urbano, a precariedade das habitações com as problemáticas de exclusão social (UN-Habitat, 2008). 0 fenômeno da cidade informal é um problema estrutural da formação da cidade brasileira que depende de razões históricas (Buarque de Hollanda, 1936; Santos, 1996; Villaça, 2001) e dinâmicas econômicas globais (Davis, 2006; Harvey, 2011; Sassen, 2010). As condições de vida nas zonas urbanas afetam a maioria da população, e as cidades são as bases e o palco das mudanças atuais e do futuro da sociedade e da economia.

Nesse cenário, ganham grande importância todas as pesquisas que abordam não só as dinâmicas sociais, econômicas e de transformação física das áreas informais, mas também aquelas que analisam as políticas que lidam com essa realidade de exclusão, tentando encontrar caminhos de construção da cidadania.

0 presente artigo visa examinar as dinâmicas de produção da cidade informal e de construção de políticas para sua requalificação integrada no contexto brasileiro. A análise e a avaliação crítica vão contribuir para o processo experimental de determinação de políticas públicas eficazes para a gestão e requalificação das áreas informais: concentram-se no contexto brasileiro, mas os resultados são interessantes para toda América Latina, por apresentarem, os países do continente, dinâmicas semelhantes, devido a causas parecidas em processos de globalização homólogos. As reflexões sobre a estruturação dos processos de planejamento participativo são importantes também como contribuição para o debate internacional sobre os processos de democratização da sociedade.

0 artigo vai primariamente definir o contexto e desenvolver algumas análises críticas a respeito do fenômeno da construção da cidade brasileira e das áreas informais a partir das análises desenvolvidas por autores como Santos (1987, 1996), Maricato (2001) e Villaça (2001, 2012). Procuraremos também entender em que forma as políticas de requalificação urbana foram concebidas como uma oportunidade para fortalecer a democracia em nível local. Secundariamente, são apresentados os resultados da elaboração do Plano de Bairro para Nova Constituinte na cidade de Salvador, capital do Estado da Bahia. Nova Constituinte é um bairro da periferia da cidade, caracterizado pela falta de infraestruturas primárias e secundárias, por uma forte degradação ambiental e uma situação social problemática. Vem apresentada a interpretação do processo de construção de uma metodologia para a requalificação das áreas informais da cidade, através da participação da população na elaboração do plano. Trata-se de um projeto- piloto, que permite testar a aplicação das teorias e metodologias participativas que podem contribuir para a eficácia das políticas de inclusão social e integração urbana. A proposta e o desafio são que a transformação física se torne um momento de fortalecimento da comunidade local e da cidadania. 


\section{Cidades em fragmentos}

Hoje no Brasil mais de $80 \%$ da população vive em área urbana (IBGE, 2010): em pouco tempo o país prevalentemente agrícola transformou-se em um país urbanizado. É claro que uma transformação tão rápida implicou profundas consequências qualitativas. Os resultados são bem visíveis: as disparidades estão refletidas em configurações socioespaciais do território e do espaço urbano contrastantes. Segundo Maricato (2001), a globalização tem simplesmente reforçado as características que marcaram historicamente o processo da urbanização brasileira: a desigualdade regional e a exclusão territorial. A cidade brasileira é uma cidade dividida, fragmentada, desigual, esquizofrênica, composta de muitas ilhas marcadas pela qualidade de seus imóveis, pela presença (ou ausência) das infraestruturas e serviços, pelo nível de manutenção do espaço público, pelas condições de segurança (Villaça, 2012). Na cidade brasileira, muitas vezes coexistem bairros com infraestrutura impecável, reservados às residências de luxo, com ao lado, bairros sem saneamento básico, marcados por graves problemas ambientais, cuja população é composta de pobres e desempregados.

Se as cidades e as metrópoles da América Latina são muito semelhantes nas estruturas espaciais, também é verdade que cada cidade traz escrita na sua forma a herança de seu passado colonial, sua inclusão ou exclusão aos diferentes ciclos econômicos e sua capacidade de seguir o ritmo do mercado global. A cultura, a história, a colonização, a religião são fatores que têm um efeito profundo na forma de organização do espaço urbano e nos mecanismos de construção da cidade. É em função desses dois componentes que se estrutura a cidade brasileira contemporânea: uma tensão permanente entre local e global, entre dinâmicas políticas e sociais estruturadas em séculos de história e uma necessidade de apressar-se a um modelo global de desenvolvimento, modernidade e bem-estar; um conflito em curso entre a remoção de todas as barreiras (de mercado, mas também sociais e culturais) e a construção de novos muros de divisão do espaço. Tudo isso na cidade brasileira tornou-se claro, explícito, visível no contraste entre super luxuosos arranha-céus ao lado de bairros miseráveis, na dificuldade do transporte público para manter o ritmo das massas trabalhadoras por um lado e a frota de aeronaves de grandes empreendedores sobrevoando os céus de São Paulo, afastando-se mesmo fisicamente em relação ao mundo comum e real.

Nos meses antecedentes a Copa do Mundo 2014, a mídia internacional apontou para 0 violento processo de remoção das favelas das áreas interessadas pelo evento nas maiores cidades do país (Magalhães, 2012). A cidade sempre foi o instrumento e produto do desenvolvimento social e econômico, mas, hoje, as políticas urbanas são vistas mais do que nunca como uma componente do desenvolvimento econômico: as transformações que afetam o espaço urbano vão cada vez mais no sentido de tornar a cidade "o apoio melhor possível" às exigências do mercado internacional, celebrando o fim da dimensão política da intervenção urbana (Harvey, 2011). Assistimos assim a deriva do "direito à cidade", garantido apenas para aqueles que contribuem para o aumento da produtividade urbana: esse torna-se o parâmetro para que os habitantes da cidade possam se integrar no espaço econômico. 
A construção espontânea da cidade manifesta-se em formas diversas e tem diferentes nomenclaturas que definem suas características específicas: favelas, cortiços, loteamentos, vilas. Nascem em prédios abandonados, em terrenos públicos ou privados não utilizados, em trechos de terras sem valor econômico (nas margens dos rios, nos espaços intersticiais entre as infraestruturas de mobilidade, etc.), sem qualquer autorização ou serviço básico. A exclusão é um fenômeno complexo que envolve uma parte consistente da população urbana no Brasil: significa impossibilidade de ter acesso a uma casa digna, a um ambiente urbano de qualidade, aos serviços fundamentais de saneamento básico, saúde, educação, ao emprego e no geral as ofertas culturais e de participação política que a realidade urbana deveria ter.

0 debate acadêmico e as políticas oficiais no Brasil, tanto em nível federal como das autoridades locais, ocuparam-se desde a transição democrática (1985) do tema da exclusão urbana, seja nos aspectos políticos e sociais, seja naqueles técnicos. A vontade de ampliar as formas de participação democráticas levou até a definição de novos princípios e a experimentação de programas que, através do envolvimento da população, tentam resolver as problemáticas urbanas.

\section{Cidadãos, exclusos ou invasores?}

Um número crescente de pessoas reside ilegalmente, ocupa seu espaço dentro do tecido urbano de forma ilícita, não respeitando algum regulamento oficial. Mas a exclusão não se limita à questão habitacional; essas pessoas são muitas vezes afastadas dos diferentes aspectos que abrangem uma vida urbana adequada: "fatores quantificáveis e não, tais como o voto político, uma casa segura e de boa qualidade, a segurança e o estado de direito, a educação de qualidade, serviços de saúde a um custo razoável, transporte digno, renda adequada e acesso ao crédito e a atividade econômica" (Task Force, 2005, p. 51).

Segundo a socióloga Vera Telles, aconteceu uma desmontagem dos conceitos de cidadania e de direito em relação à reconfiguração do mercado do trabalho, abrindo caminho para a "cidadania salarial". Sempre segundo a autora, a perspectiva ética da cidadania está se tornando "uma espécie de afirmação ritualística que confunde política e bons sentimentos, confunde as diferenças entre direito e ajuda humanitária, entre cidadania e filantropia" (Telles, 2001, p. 35). No momento que não é mais reconhecido o direito universal a ser parte da vida urbana, reconhecido apenas para aqueles que conseguem entrar no ciclo econômico, as formas de sobrevivência resultantes da exclusão do sistema urbano vêm sendo consideradas ilegais, senão até imorais. Isso significa que, quando as políticas urbanas lidam com a parte excluída da cidade, muitas vezes precisam justificar a escolha das decisões referindo-se aos valores da ajuda humanitária e não aos valores do direito do cidadão.

A representação da cidade é uma confusa construção ideológica que torna a condição de cidadania um privilégio e não um direito universal: parte da cidade toma o lugar do tudo. A cidade da elite representa e esconde a cidade real (Arantes, Vainer e Maricato, 2000). A legislação urbanística aplica-se à cidade oficial: 
os serviços de manutenção dos espaços públicos, da pavimentação e da iluminação na cidade formal são eficazes. A mesma coisa ocorre na aplicação das leis. É comum que apenas uma parte do plano seja realizada ou que as previsões sejam aplicadas a apenas uma parte da cidade: sua aplicação segue a lógica da cidadania restrita a alguns.

Segundo Santos (1987), foi a velocidade e a combinação dos processos de abandono do campo, a migração, a urbanização e o crescimento econômico acelerado que levaram à formação, não do cidadão, mas do consumidor, do usuário. 0 consumidor "alimenta-se de parcialidade, está satisfeito com as respostas setoriais, o seu alcance é limitado, não tem direito ao debate sobre os objetivos das ações, públicas ou privadas" (ibid., p. 42) e ignora seus próprios direitos. É possível afirmar que a questão da falta da cidadania depende do processo de criação do Estado: todas as formas de organização política e econômica foram importadas da Europa, reformuladas ou simplesmente adaptadas, sem um processo de metabolização no panorama histórico, cultural e político próprio do país (Buarque de Hollanda, 1936). Isso significa que se criou um Estado democrático, baseado em conceitos de igualdade e solidariedade em um país onde a herança colonial ainda é forte, apesar de ser dissimulada. 0 Brasil é ainda um país profundamente marcado por diferenças raciais e econômicas. A formação cultural e política no Brasil tem sido tradicionalmente autoritária, hierárquica, baseada em um regime de propriedade e escravidão (Freire, 1970). Santos observa, com especial atenção ao caráter cultural do direito, que "sem dúvida, a cidadania se aprende. Assim, torna-se um estado de espírito, enraizado na cultura. A metamorfose dessa liberdade teórica em direito positivo depende de situações concretas" (Santos, 1987, p. 8). 0 direito de ter direitos é expresso ou negado em espaço físico, sacrificado ou reclamado a partir de lugares concretos: morar, estudar, trabalhar, brincar e viver de forma saudável, mover-se, decidir, participar.

A invasão das terras urbanas no Brasil é uma parte intrínseca do processo de urbanização. A produção ilegal da maioria dos domicílios urbanos, como meio de sobrevivência, é funcional à conservação do baixo custo de reprodução da força de trabalho, e por um mercado imobiliário especulativo, que se sustenta na estrutura fundiária arcaica (Rolnik, 2003). A terra é um nó na sociedade brasileira, mesmo na cidade: o latifúndio, por exemplo, resistiu ao longo do tempo a todos os debates e às propostas de mudança. A ocupação ilegal de terras urbanas é, na realidade, estrutural e institucionalizada pelo mercado imobiliário, reforçada pela ausência de políticas sociais. A realidade é disfarçada atribuindo a uma parte da sociedade a responsabilidade por aquilo que é 0 resultado de um processo que alimenta as desigualdades sociais. Na mídia, dominada pela classe dirigente, a invasão de terra é atribuída às ações da esquerda radical e dos movimentos populares que querem desafiar a lei. A conquista de um teto por parte dos pobres da cidade vem muitas vezes descrita como atividade não só ilegal, mas também permeada por um espírito de desonestidade (Magalhães, 2012). As favelas foram estigmatizadas desde o início, como causa e origem da desordem urbana e não como uma realidade decorrente do sistema excludente da sociedade brasileira (Alvito e Zaluar, 2004). As representações das causas da 
violência atribuída à classe pobre contribuem para a construção de imagens coletivas, que por sua vez contribuem para impedimento da classe popular de transformar o acesso aos valores da ordem igualitária, para se tornar legítimos atores sociais. Ao mesmo tempo, as efígies da violência incentivam a classe media à adoção de um comportamento de secessão urbana, traduzida na busca de fronteiras simbólicas e materiais que as separem do mundo das classes populares. Segregação não é apenas a separação espacial, concentração de um segmento da população em territórios bem definidos, mas também implica a institucionalização de sua inferioridade.

A exclusão mais profunda é escondida atrás do prejuízo ligado ao lugar da cidade onde cada cidadão mora, o 'estigma territorial', como definido por Wacquant (2007). 0 homem que vive na favela ou num bairro pobre tem vergonha de suas origens, vergonha alimentada pela mídia, pela atitude agressiva e discriminatória da polícia, pela exclusão das opções de financiamento rateado. Na vida cotidiana, são infinitos os momentos em que um favelado percebe ser tratado como inferior em termos concretos. A favela é "território não apenas da pobreza, mas também do isolamento social promovido pelo estigma dos bairros pobres, da marginalidade das redes de informação, que permitem entrar no mundo do trabalho, e da falta de acesso a determinados empregos por causa da discriminação" (Queiroz Ribeiro e Alves dos Santos, 2003, p. 35). 0 narcotráfico continua a explorar esse sentimento de inferioridade e de exclusão, a especular sobre a pobreza e a falta de oportunidade, sobre o desejo de afirmação e de participação à cultura dominante do consumo.
Nesse cenário, existem porém experiências muito positivas de valorização da identidade da favela, que saem mesmo das realidades vítimas do narcotráfico, para demonstrar a diversidade e a complexidade cultural que sempre permeou os Morros (Alvito e Zaluar, 2004). Começando das escolas de samba e dos blocos de carnaval, passando por todas as organizações de bairro que procuram construir condições sociais e econômicas melhores, até as associações mais recentes, cujo objetivo é valorizar a cultura e a identidade desses espaços excluídos da cidade. Estudar uma favela hoje é, sobretudo, uma forma de combater um pensamento comum e acadêmico que reproduz apenas uma parte das imagens, ideias e práticas correntes. Significa mapear as fases de desenvolvimento de um mito urbano. As políticas centrais e locais mudaram gradualmente sua visão em relação à ocupação ilegal de terras urbanas. Inicialmente o fenômeno era considerado como uma doença da cidade, um câncer a ser erradicado. Posteriormente as políticas centrais chegaram ao reconhecimento de uma realidade de fato que representa a natureza excludente da cidade. As mais recentes tentativas de intervir através de projetos de regeneração, melhorias infraestruturais e recuperação ambiental, nascem e estão estruturadas com o objetivo de integrar no tecido urbano e social essas ilhas de informalidade.

Em nível internacional assistimos, já a partir dos anos 1980, a uma mudança de estratégia através da promoção de uma abordagem multissetorial para os problemas urbanos, não somente limitada à dimensão física. Essa abordagem começa a lidar com a complexidade da realidade da pobreza e da exclusão, o que requer políticas locais integradas 
(Allegretti, 2000, p. 54). A nova Constituição de 1988 representa um momento fundamental para a questão urbana no Brasil: ela inclui um capítulo sobre política urbana que define, através dos artigos 182 e 183, a função social da propriedade privada urbana, proporcionando a existência de instrumentos urbanísticos, que interferindo no direito de propriedade, têm o objetivo de quebrar a lógica da especulação imobiliária (Ministério das Cidades, 2004). Obteve-se o reconhecimento do direito dos favelados ao acesso à terra urbana e habitação, e vários programas de regularização de favelas têm sido formulados pelas autoridades locais com o objetivo de promover tanto a urbanização quanto a legalização. Mas a conquista maior foi, depois de um trabalho decenal desenvolvido pelo Fórum da Reforma Urbana, a aprovação da lei $n^{\circ} 10257$, de 2001, conhecida como Estatuto da Cidade, que tem o objetivo de criar instrumento urbanístico para aplicar os artigos 182 e 183 da Constituição. Com a lei, criam-se novos instrumentos de política urbana, garantindo a promoção da integração social e espacial das cidades. Entre esses, destaca-se o instrumento das Zonas Especiais de Interesse Social - Zeis, como meio de democratizar o acesso à terra urbana: usado de forma pioneira pelo governo do Recife, é um instrumento capaz de criar uma legislação flexível e aplicável em áreas consideradas de interesse social, seja em terras públicas ou privadas. À distância de 10 anos da aprovação da lei, têm sido feitas muitas críticas com respeito à aplicação real dos princípios pelos governos locais. A dificuldade de aplicá-los, como aponta Maricato (2010), não é devida a qualquer defeito dos instrumentos, mas é ligado aos interesses políticos e econômicos em causa.
Rolnik (2013) enfatiza o fato de que, muitas vezes em relação à regularização fundiária de favelas, os municípios continuam a se referir mais à 'questão social' do que ao do direito protegido por instrumentos específicos. Apesar disso, o Estatuto da Cidade representa ainda um passo em direção a "uma grande utopia: a restrição do direito de propriedade individual, tendo em vista o interesse público" (Maricato, 2010 , p. 6) e, certamente, uma grande contribuição para a construção do 'direito à cidade' em todas as latitudes.

\section{Plano de Bairro ${ }^{1}$}

O Plano de Bairro é uma política urbana promovida pela Secretaria de Habitação ${ }^{2}$ - Sehab da cidade de Salvador entre 2006 e 2007: um programa experimental, que visava a criação de ferramentas para a requalificação urbana das áreas informais em uma abordagem integrada e com a participação da população.

Salvador é uma importante referência para o Brasil, uma das cidades coloniais mais antigas da América Latina, a primeira capital do Brasil e a segunda do Império Português. Sua densidade histórica e cultural lhe confere uma forte identidade no processo de transformação contemporâneo. Conta uma população de 3 milhões de habitantes e apresenta as características de fragmentação e exclusão da urbanização brasileira. Segundo os dados disponíveis no Plano Diretor de Desenvolvimento Urbano - PDDU ${ }^{3}$ de Salvador (PMS, 2008), cerca de dois terços dos habitantes da cidade vivem em assentamentos caracterizados pela informalidade e pela falta de infraestrutura. 0 mesmo plano identifica 76 áreas 
da cidade como Zeis, ${ }^{4}$ prevendo a elaboração de planos, programas e projetos específicos de regularização fundiária e melhoria das áreas sujeitas a risco hidrogeológico ou incorretamente localizadas.

Para intervir em uma dessas áreas, nasce o Plano de Bairro para Nova Constituinte, com a participação dos habitantes na elaboração do projeto de transformação. 0 programa previa, também, o desenvolvimento da metodologia para a elaboração de outros planos similares, sempre com a participação dos moradores e a produção de um manual para implementação desse instrumento em outras áreas com características semelhantes (PMS/Sehab, 2005). Essa metodologia tinha que conter as diferentes formas de articulação, divulgação e envolvimento da população, com o objetivo de alcançar uma participação mais ampla possível no processo de identificação e caracterização do local em seus diversos aspectos.

0 Plano de Bairro tinha que ser composto de um Plano Urbanístico Específico e de um Estatuto de Bairro, que estabelecesse normas e critérios específicos de classificação do uso do solo, construção, manutenção, estruturas comunitárias, concordado coletivamente entre os habitantes e o poder público local. 0 Plano Urbanístico Específico tinha que ser um apoio aos programas e projetos de infraestrutura urbana decorrentes da integração e convergência das propostas dos diferentes atores que operam na área, com o objetivo de estabelecer um pacto social que permitisse a ocupação do solo, respeitando as restrições urbanísticas e ambientais devidas à localização.

Entre os resultados esperados do Plano de Bairro, destacam-se o fortalecimento da organização social e comunitária, a promoção das entidades locais, reforçando o sentimento de cidadania e a consciência individual e coletiva, incluindo a definição de regras de coexistência e de utilização do espaço urbano. A população foi considerada como um sujeito ativo, capaz de organizar uma rede de informações e principalmente de estimular o debate e a participação dos moradores em todas as fases da elaboração do Plano. A política pretendia superar uma abordagem setorial e incluir todos os setores administrativos que atuam diretamente na área de habitação. ${ }^{5}$

A área escolhida para a experiência-piloto foi a de Nova Constituinte, no Subúrbio Ferroviário da Cidade: uma área ocupada desde 1988 onde moram cerca de 12.000 pessoas. $^{6}$

Os objetivos do programa eram, portanto: - Formar os técnicos da Prefeitura de Salvador e, no específico, das Secretarias de Habitação (Sehab) e de Planejamento, Desenvolvimento Urbano e Meio Ambiente (Seplam) para atuar nos bairros informais de Salvador de forma planejada e concordada com as necessidades e os interesses dos habitantes;

- Analisar e descrever a área, a fim de desenvolver o Plano Urbanístico Específico e desenvolver uma metodologia para a elaboração dos Planos de Bairro, através da participação dos moradores;

- Definir os parâmetros próprios da área, através do instrumento do Estatuto de Bairro, tornando-os compatíveis com a Lei de Uso e Ocupação do Solo (LOUOS) em vigor.

0 programa formou-se em várias etapas, porém, as reflexões aqui apresentadas focam-se na etapa da estruturação do processo participativo. 


\section{A participação tentada}

Os objetivos da participação em Nova Constituinte eram três: (1) de um lado, se pretendia envolver os moradores na definição das problemáticas e das transformações necessárias para o bairro, para que essas fossem adequadas à realidade. Além disso, (2) pretendia-se estimular um processo de análise crítica em relação à complexidade da gestão urbana e ao fenômeno da segregação socioespacial, para contribuir ao empowerment da sociedade, na conquista do direito à cidade e à cidadania. Contemporaneamente, (3) experimentava-se a metodologia para conseguir os objetivos declarados, que fossem eficazes e aplicáveis em outras áreas da cidade (Uneb/Sehab, 2006). Essas três componentes foram sempre presentes no trabalho de definição dos instrumentos adequados, através de um contínuo processo de avaliação e redefinição. 0 caráter experimental da elaboração do Plano de Bairro refletiu-se no andamento do processo participativo, no contínuo aperfeiçoamento das técnicas utilizadas e na tentativa de encontrar o modo mais eficaz para que os habitantes participassem de forma ativa e consciente na construção do plano. 0 fato de esse processo ter sido construído no ambiente universitário ${ }^{7}$ agregou um valor a mais; a elaboração do Plano de Bairro foi uma ocasião de confronto e colaboração entre o ambiente da produção científica, a administração pública e a sociedade.

A metodologia de envolvimento dos habitantes foi construída através de diferentes atividades que podem ser descritas nas cinco categorias seguintes:
1) Informação (esclarecer, explicar, divulgar)

Um aspecto fundamental para o sucesso de um processo de participação popular é a informação. Quando o público-alvo não tem acesso aos canais de comunicação da mídia (imprensa, internet, etc.), como no caso dos moradores de Nova Constituinte, é necessário encontrar outros canais, para que a informação possa alcançar o maior número de pessoas. No caso, a experimentação em Nova Constituinte serviu-se da elaboração de panfletos e cartazes distribuídos no bairro, diretamente nas mãos das pessoas ou pendurados na rua principal e em lugares como mercados e igrejas. Essa divulgação do programa e dos encontros foi realizada pela equipe que andava pelas ruas do bairro distribuindo panfletos, parando para conversar com os moradores, explicando o que era o Plano de Bairro e convidando as pessoas para participar das atividades. Esse tipo de técnica, definida para Nick Wates "outreach", ou seja, "alcançar fora", baseia-se na ideia de inverter o costume que o cidadão tem que ir até os serviços da administração: nesse caso, é a instituição que vai até o cidadão para lhe oferecer serviço (Sclavi, 2002, p. 226). Da mesma forma, nasceu a decisão de entrar em contato com as principais entidades da sociedade presentes no bairro, com o objetivo de conhecer as atividades que desenvolvem e de convidá-los para participar do processo. Entrou-se então em contato com as lideranças comunitárias que foram fundamentais no processo participativo e que acompanharam a equipe em todas as atividades. Em especial, esses encontros foram importantes para o conhecer a realidade do bairro e para a realização de pesquisas para coletas de dados. 
2) Comunicação Interpessoal (presença, disponibilidade, confiança)

A presença dos técnicos da equipe no bairro, sua disponibilidade em responder perguntas e esclarecer aspectos sobre o programa, enfim, a simples comunicação com a comunidade local, foram elementos substanciais para a criação de uma relação de igualdade e confiança com os moradores. A falta de trânsito nas ruas do bairro, permitiu que essas fossem o espaço ideal para que as pesquisas fossem realizadas. Muitos habitantes interessavam-se na presença da equipe e procuravam entender o objetivo da visita; duas atitudes eram preponderantes entre eles, a desconfiança e o reclamo. 0 fato de a equipe ser da Universidade ajudou a limitar as acusações de responsabilidade e os lamentos que teriam sido reservados aos técnicos da prefeitura. A equipe conquistou a confiança na comunidade, escutando o que a população local necessitava, e foi instaurado um diálogo aberto, o que favoreceu ao desenvolvimento das pesquisas. Especialmente na fase de conhecimento, cujo objetivo era a aproximação da equipe à realidade da área, foi utilizada a técnica da observação de campo participativa, um tipo de observação não sistemática que tenta recolher e gravar os dados da realidade visível sem utilizar os meios mecânicos especializados, ou seja sem planejamento e controle. Essa técnica permaneceu válida nas fases sucessivas durante todos os encontros entre a equipe e os moradores, dentro e fora do bairro. Demonstrou-se um bom instrumento de sensibilização justamente porque o técnico da equipe coloca-se como parte da comunidade à frente das situações propostas nos encontros e nos eventos de mobilização. A equipe não traz propostas pré-determinadas, mas caminha paralelamente com a população na busca das soluções aos seus problemas.

3) Formação (criar as condições para o confronto)

Em contextos problemáticos é comum que os habitantes se acostumem ao lamentar acrítico, a inculpar as autoridades sem elaborar uma análise dos fatores que são a base para a transformação. Portanto, considerou-se necessária uma espécie de 'abertura formativa'; através da realização de um seminário, cujo tema, o conceito sociológico da participação comunitária, tinha como objetivo esclarecer a utilidade dos instrumentos de planejamento e das técnicas de participação popular. 0 intuito era, através desse, estimular uma atitude crítica e reflexiva da parte dos habitantes, para que esses fossem mais conscientizados em relação aos seus próprios direitos e sobre a importância da própria contribuição à conquista das meIhores condições para o bairro. Os seminários seguintes aprofundaram os temas relativos ao planejamento urbano e a elaboração do Plano de Bairro.

4) Diálogo (respeito, valorização e troca)

Entre as atividades estruturadas com o objetivo de construir momentos de diálogo, foram propostas as visitas do Bairro e os encontros temáticos. Segundo a socióloga Sclavi, "a visita do bairro presume e afirma na prática, uma relação de reciprocidade entre profissionais e moradores que elimina relações de dominação-dependência, seja de uma parte que da outra, que aliás reconhece uma inteligência recíproca, uma possibilidade de aprendizagem para as duas partes" (2002, p. 206). A visita representou um momento fundamental para valorização dos saberes não expertos e para dar 
início a um verdadeiro momento de interação e diálogo.

Os encontros temáticos foram uma estratégia metodológica escolhida por a equipe técnica para tratar de maneira eficaz a grande quantidade de informações que pretendia-se discutir com a população, utilizando uma linguagem acessível sobre os aspectos da vida urbana. Surgiram da reformulação do instrumento do Seminário e foram organizados através de discussões de grupo: tornaram-se momentos para aquisição de novas informações, para a definição do Plano de Bairro e para compreender as prioridades da população em relação às intervenções a serem planejadas.

\section{5) Representação}

As oficinas de representação propostas e realizadas juntas aos moradores de Nova Constituinte surgiram da necessidade de envolver e valorizar as diferentes componentes etária e de gênero que existem na comunidade e de fortalecer a capacidade de representação e a identidade do bairro. Seminários e assembleias são tipos de encontros que conseguem envolver uma parte da população bastante homogênea: a maioria adultos com idade entre 20 e 50 anos. A equipe pretendia incluir no processo participativo as outras componentes da população (como crianças, adolescentes e idosos); esses participavam em número inferior aos seminários. Além disso até então o processo participativo tinha utilizados muito pouco de instrumentos de representação do território, proporcionando uma maior dificuldade de comunicação com os moradores, e, portanto, uma menor capacidade de descrever e planejar as transformações do bairro. Muitos dos encontros foram construídos totalmente em cima da comunicação verbal, dificultando muitas vezes a identificação de problemas e de lugares específicos, o que foi um dos limites maior do processo participativo. 0 objetivo das oficinas foi então envolver as componentes sociais específicas através da representação do bairro. Foram utilizadas três diferentes técnicas: a fotografia com um grupo de mulheres, a representação tridimensional, ou seja a construção de maquetes com um grupo de adolescentes, e o vídeo com crianças e idosos. As oficinas resultaram-se em uma metodologia muito interessante, capaz de envolver os moradores de forma mais profunda no processo de elaboração do plano.

\section{Os limites do processo}

Os objetivos da participação do Plano de Bairro não foram totalmente alcançados. Os limites podem ser encontrados tanto nos métodos de implementação e de gestão do processo como em condições implícitas à realidade de intervenção. A seguir vem apresentada uma síntese crítica.

1) Resistência ao processo. Um dos maiores limites do processo participativo foi a efetiva participação da comunidade local. Essa resistência é produto de diferentes variáveis: aspectos sociais como o nível de alfabetização e fatores culturais. Muitas vezes os diferentes estigmas sofridos pela população que mora nas periferias das metrópoles (Wacquant, 2007) são autorreproduzidos e contribuem a um autoafastamento das possibilidades de mudanças. Além disso, a carência das escolas, creches, transportes públicos, espaços comunitários, representa a ausência do Estado nas periferias 
da cidade e contribui à falta de confiança da população nas possibilidades da participação e da transformação efetiva da realidade. Essa desconfiança define o quadro das dificuldades na elaboração desta metodologia. A ausência do Estado soma-se à frustração da população em relação às expectativas não cumpridas. Nova Constituinte foi objeto de outras políticas públicas de administrações anteriores, mas as ações propostas nunca foram implementadas. Por exemplo, a proposta de "Intervenção para o desenvolvimento da Invasão Nova Constituinte", apresentada no 1992 pela prefeitura, consistia num conjunto de intervenções que garantissem as condições básicas para habitação na área (PMS/Sehab, 2006). Orientada pelo projeto "Penetração na área e mobilização comunitária", o programa ocupava-se não só das habitações existentes, mas previa o assentamento de outras pessoas de baixa renda, provindo das áreas de risco de outros bairros da cidade. Além de intervenções relativas às infraestruturas como aberturas de ruas, pavimentação, drenagem, iluminação e construção de estruturas comunitárias. 0 plano previa ações em nível educativo e de desenvolvimento socioeconômico, como a construção de um centro comunitário, de um núcleo de produção de artesanato e uma lavanderia comunitária. 0 plano nunca foi realizado aumentando a desconfiança dos moradores em relação a esse tipo de intervenções. Também no caso do Plano de Bairro não existia a certeza da efetiva implementação, não havendo ainda recursos disponíveis para as intervenções a serem planejadas. A descontinuidade dos programas está ligada à alternância dos governos e às possibilidades e à vontade política de continuar a investir nas intervenções planejadas. Enfim, adiante da necessidade de ações urgentes como saneamento básico e serviços públicos, a população quer ter resultados a curto prazo: por consequência toda participação na construção de um plano que necessita de longo prazo para ser instaurado resulta pouco atrativa. As condições de pobreza, exclusão social e estigma prejudicam na maioria dos casos a articulação coletiva, fonte de pressão popular capaz de monitorar e cobrar a aplicação dos direitos. Primeiramente pela já mencionada componente de autorreprodução do estigma e da consequente dificuldade de sentir-se protagonista da própria mudança. Secundariamente pela desconfiança em relação ao Estado, a política e pela atitude clientelista e da circunstância que não contempla o compromisso constante na construção das transformações. A fraca presença das organizações comunitárias no bairro indicava uma indiferença generalizada da população em relação aos problemas, pouca confiança na atividade de reivindicação política e uma atitude tradicional de clientelismo.

2) Gestão do processo. 0 programa do Plano de Bairro em termos teóricos representa um passo fundamental no estabelecimento de um processo de inclusão social e regularização urbanística, porque, por um lado procura ir além da abordagem setorial da política urbana da prefeitura e, por outro, introduz um conceito de participação da população que não se limita ao aspecto consultivo, mas os considera protagonistas das tomadas de decisões. Infelizmente existiu uma discrepância entre os objetivos e os pressupostos do programa e a realidade da gestão do processo por parte da administração pública. É importante reconhecer a Sehab o mérito de ter promovido uma política de inovação como o Plano de Bairro, mas também é 
preciso refletir sobre as dificuldades que a Secretaria demonstrou na efetiva implementação e gestão do programa. A distância entre a teoria e a prática caracterizou o Plano de Bairro desde o início. É importante resumir os pontos críticos encontrados durante o cumprimento do programa para que possamos obter melhorias nos métodos das abordagens:

a) Considerando que a formação dos técnicos locais para trabalhar nas áreas informais e nas Zeis constituía um dos objetivos principais do programa, os trabalhos tinham que ser desenvolvidos com a participação direta dos técnicos locais. Essa participação, houve realmente apenas nas primeiras reuniões com a população: foi um grande limite para a realização dos objetivos, e foi necessária uma modificação dos métodos de trabalho já pré-definidos.

b) Um outro obstáculo foi a falta de transparência por parte da Sehab durante o inteiro processo: uma dificuldade mais estrutural da administração local que dos específicos funcionários. Uma substancial incapacidade da estrutura organizada verticalmente, de gerir um processo de tipo horizontal, ou seja, de criar verdadeiramente um espaço onde a tomada de algumas decisões fosse resultado do processo participativo.

c) Além disso, embora o programa do Plano de Bairro enfatizasse a importância de uma abordagem inter-setorial nas políticas urbanas, na verdade, a atitude setorial demonstrou-se ser tão estrutural na gestão do território que resultou quase impossível dialogar e trabalhar com as outras secretarias.

d) Em última análise, a complexa burocracia, que caracteriza quase todos os governos, tem criado obstáculos e atrasos que impactaram negativamente o processo de desenvolvimento do projeto: 0 atraso nos pagamentos, nas transferências de dinheiro para atividades e no salário dos profissionais da equipe contribuiu para as fraquezas do processo participativo.

3) Metodologia. Em relação à metodologia desenvolvida pela equipe e voltada à participação dos moradores, é possível sublinhar alguns aspectos que influíram negativamente na definição da mesma:

a) A escassa presença dos profissionais da equipe no bairro com continuidade. Para estabelecer uma relação de confiança com os moradores era necessária uma presença constante durante o desenvolvimento do processo. Isso não aconteceu por duas causas principais: os profissionais da equipe, por um lado, não eram satisfeitos pelas condições de trabalho (atrasos nos pagamentos, etc.), mas principalmente eram sujeitos a sensações de insegurança pessoal nas visitas ao bairro. 0 estigma de bairro periférico leva consigo todo um imaginário ligado à violência e de consequência ao medo; esse imaginário é tão profundo nas pessoas que não vivem nas periferias que impede a percepção dos riscos reais, que, por exemplo, no caso de Nova Constituinte, não eram maiores que em outros bairros da cidade.

b) 0 pouco conhecimento da realidade dos assentamentos informais por parte dos profissionais e a consequente dificuldade de encontrar linguagens adequadas para uma comunicação eficaz. Esse representou com certeza o limite metodológico maior. Considerando o grau de alfabetização da população de Nova Constituinte, as temáticas abordadas nos debates resultavam complexas e de difíceis entendimento: de fato as dinâmicas urbanas e os instrumentos urbanísticos resultam complexos também para os profissionais do setor. 
Era então necessário um esforço para simplificar, sintetizar e utilizar uma linguagem comum para apresentar alguns conceitos de forma eficaz. Isso prevê uma formação específica dos técnicos e dos profissionais sobre técnicas de comunicação através do uso das imagens, de esquemas e de outras metodologias. Algumas tentativas foram feitas e foram até bem-sucedidas, mas substancialmente teria sido necessária uma específica formação dos profissionais antes do processo e um planejamento das metodologias de comunicação.

c) Enfim, mas não menos importante, foi o uso insuficiente da representação do território nos debates e trabalhos com os moradores. Discutir sobre potencialidades e problemáticas de um território sem poder "vê-lo" ou "tocá-lo" com mão limita fortemente os resultados esperados. Esse específico aspecto teria que ter sido planejado antes do início do processo em vez de durante o desenvolvimento do mesmo, para permitir que a maquete e outros suportes gráficos fossem melhor utilizados.

4) Resultados. Um ano depois da elaboração do Plano para Nova Constituinte aconteceu uma mudança da administração da prefeitura. Os resultados positivos do projeto foram esquecidos e as previsões de continuidade nunca foram aplicadas. Alguns moradores, que haviam participado de forma mais ativa à elaboração do projeto, foram reivindicá-lo como patrimônio da comunidade junto à Universidade. Infelizmente essa reivindicação não obteve sucesso, e o plano ficou mais uma vez sem implementação. Em 2013, o bairro se tornou novamente objeto de projetos, dessa vez por parte do governo do Estado (Sedur). Numa visita à área, foi possível constatar que as condições gerais do bairro haviam piorado e que as intervenções do Estado tinham sido limitadas à construção de espaços de lazer, um campo de futebol e uma praça. Tudo isso sem nenhuma participação da população e com muita demora, como relatado por antigos moradores participantes do processo participativo para o Plano de Bairro.

\section{Reconsiderar a participação}

A partir da experiência descrita e das avaliações sobre seus limites, surgem umas considerações sobre as bases necessárias para estruturar processos de participação eficazes. Os termos 'participação' e 'democracia' no Brasil são amplamente aproveitados por diversos setores sociais. É possível encontrar a utilização desses conceitos nos programas governamentais de praticamente todos os partidos políticos, nem sempre usados com o mesmo significado. 0 mundo da participação está constantemente em mudança e é caracterizado pela natureza às vezes contraditórias. Se, por um lado, a participação dos cidadãos na política urbana tornou-se uma preocupação generalizada por causa da crise do sistema tradicional de representação política e das mudanças da "gramática da vida e do espaço da cidade", reconhecendo a necessidade de "uma compreensão mais sutil das necessidades" e uma "exigência de qualidade da política" (Paba e Perrone, 2004, pp. 34-35), por outro, não passou muitas vezes da simples busca do consenso em relação a planos ou projetos já definidos. Pois existe uma profunda diferença entre esse tipo de participação e os processos que verdadeiramente tentam abrir espaços de debate e 
construção da inclusão social nos territórios da exclusão urbana.

Por isso o propósito da investigação sobre a participação não é o estabelecimento de técnicas padronizadas ou parâmetros, mas o de criar bases culturais e teóricas que permitam experimentá-la cada vez de forma diferente e específica. Como contribuição a esse processo, são a seguir desenvolvidas três reflexões: a primeira refere-se à base imprescindível da participação nas políticas públicas, ou seja, a atitude política, a segunda sublinha o potencial de inclusão social dos processos participativos e a última aponta para criação de lugares privilegiados de construção desse desafio, os laboratórios permanentes.

\section{1) Atitude política}

"A atitude política na construção de planos determina o resultado do projeto" (Magnaghi, 2005, p. 135). A eficácia das políticas de participação consiste (1) primariamente em um planejamento a longo prazo, (2) no investimento de recursos adequados e (3) na aplicação efetiva das propostas resultantes dos processos de tomadas das decisões. Em caso contrário, os processos participativos acabam por ser desgastes de energias e recursos da sociedade e produzem desconfiança e afastamento entre os cidadãos e as instituições. Nesse sentido negativo, o caso de Nova Constituinte é significativo. No Brasil, o contexto das contínuas mudanças políticas em nível local representa com certeza um limite ao planejamento de longo prazo uma vez que a cada quatro anos mudam os objetivos, as estratégias e os funcionários. 0 investimento de recurso adequados vem como consequência. Os Planos de Bairro deveriam ser válidos no tempo, uma vez aprovados, como os outros instrumentos urbanísticos e então não depender das mudanças de governo para ser implementados, de forma a permitir também o planejamento dos recursos.

Além disso, é necessário um contínuo trabalho de formação dos funcionários e de transformação das lógicas negativas estruturais das autoridades locais (setorialidade, burocracia, etc.) para que possam ser promotores e gestores de programas verdadeiramente inovadores.

2) A participação como processo de inclusão

Um dos objetivos de processos participativos é certamente reforçar o senso cívico e ampliar os direitos da cidadania. Esse aspecto adquire um valor fundamental nas sociedades caracterizadas por uma profunda exclusão histórica de uma parte da população, como a do Brasil. A participação se torna não somente uma exigência de eficácia das políticas de transformação e requalificação urbana, como também a oportunidade de uma distribuição mais equitativa, não só de recursos, mas também dos direitos e do poder político. Obviamente não é possível reverter a direção do crescimento das cidades sem inverter o sentido das relações sociais. Como aponta Maricato, "a produção e apropriação do espaço urbano não só reflete as desigualdades e as contradições sociais, mas as reafirma e reproduz" (Arantes, Vainer e Maricato, 2000, p. 170).

A construção de um novo paradigma urbano é parte da luta por uma nova sociedade e os instrumentos participativos, quando concebidos como verdadeiros instrumentos de empowerment (Friedmann, 2004), tornam-se ferramentas fundamentais. 0 processo de formulação de um plano pode ser mais importante que o plano em si mesmo: pois a redação técnica ou legislativa, por mais inovadora que seja, 
não produz a participação política que é conseguida através de um processo participativo.

A tendência por parte das autoridades de pensar nas áreas informais como comunidades estruturadas é profundamente distorcida e é o resultado de uma visão distante e ingênua da realidade: os bairros informais e os subúrbios de fato apresentam uma variedade de necessidades, muitas vezes conflitantes. Essa tendência, esse modo de ver as comunidades, pode afetar importantes decisões políticas na sociedade, porque não considera a situação real de fragmentação social interna e, portanto, não prevê ações e métodos apropriados. Se considera-se o sentimento de pertença a uma comunidade um recurso útil para uma transformação positiva das áreas informais, é preciso olhar para uma estratégia de intervenção que vise valorizar a identidade da comunidade e seus valores.

Por isso é útil referir-se a todas as experiências concretas de participação na transformação do território: os canteiros de autoconstrução, os chamados mutirões, a criação de pequenas cooperativas de serviços para o bairro, as associações e, em geral, todas as formas de investigação-ação. 0 processo participativo, portanto, não pode limitar-se apenas ao ato de consultoria em relação às mudanças a serem feitas, mas deve envolver forças e recursos presentes no território para encontrar formas de agregá-lo e torná-lo ativo em um caminho de transformação efetivo e compartilhado (Tarsi, 2013).

3) Laboratórios permanentes

0 primeiro passo para conseguir esses objetivos é reconstruir, ou melhor, recuperar uma consciência do valor do território. Essa operação complexa e criativa deve ser fruto de um esforço conjunto de todas as partes interessadas e significa atribuir uma nova força simbólica e social ao território (Magnaghi, 2005). Somamos a isso a convicção de que as transformações do território necessitam não apenas de abordagens integradas, mas também construídas em perspectivas de longo prazo.

A partir das dificuldades metodológicas do processo participativos em Nova Constituinte antes sublinhadas, é possível afirmar a necessidade de criar entidades e estruturas que saibam administrar ao longo do tempo as diferentes fases de envolvimento, planejamento e execução de planos e sejam verdadeiros pontos de referência entre a comunidade e a administração local.

0 que no Plano de Bairro era apenas uma intuição (a constituição de um grupo de Multiplicadores que trabalhasse em conjunto com a equipe de profissionais), em outros programas torna-se uma proposta estrutural: como é o caso do Grupo Gestor e o Agente do Habitat, proposto pelo LabHab de São Paulo (LabHab, 2003), e a Agência de Desenvolvimento Local (Barthel, 2007) da experiência italiana. As agências de desenvolvimento local ou as antenas no território tornam-se sujeitos importantes para que as políticas não sejam exclusivamente de emergência, contingente e setoriais. Esses instrumentos reais de descentralização no território tornam-se catalisadores das necessidades e potencialidades locais e os instrumentos de coordenação entre os diferentes atores envolvidos na transformação. É importante que os moradores não sejam somente envolvidos no processo, mas que se tornem promotores de projetos. É preciso avançar para a criação de verdadeiros laboratórios permanentes de pesquisa e planejamento, que 
envolvam pesquisadores de várias disciplinas, técnicos das autoridades locais e representantes dos moradores. Esses laboratórios podem ser capazes de dar vida a um processo que, em primeiro lugar, recupere as peculiaridades do território e, em seguida, desenvolva e implemente pequenas ações de mudanças físicas, culturais, econômicas, educacionais. Inicialmente promovido pela administração, esses espaços de descentralização do poder deveriam, no decorrer do seu desenvolvimento, serem capazes de se autogerir, tornando-se, dessa maneira, parte da responsabilidade não só do Estado, mas de toda a sociedade civil.

\section{Considerações finais}

As metrópoles brasileiras representam um terreno muito desafiante para elaboração de políticas e programas para integrar parte da cidade e ao mesmo tempo incluir socialmente seus habitantes. As muitas experiências surgidas e desenvolvidas no país a partir da aprovação do Estatuto da Cidade e dos novos instrumentos para intervir nas áreas informais constituem uma importante bagagem que tem que ser sistematizada e aproveitada para aprender a partir dos erros e dos sucessos. A distância de quase quinze anos podemos concordar com Maricato na avaliação do Estatuto: o caráter pontual de tantas experiências constitui com certeza um dos maiores limites, mas sem dúvida a vontade política representa a condicio sine qua non para uma verdadeira mudança na gestão da parte espontânea da cidade (Maricato, 2010).

0 estudo de caso apresentado neste artigo e as avaliações dos limites encontrados na estruturação da participação dos moradores a elaboração do plano foram oportunidade para contribuir ao processo de construção de políticas públicas eficazes que, além dos objetivos de planejamento ou de transformação do território, consigam tornar-se percursos de inclusão social dos moradores. Foram sublinhados os limites estruturais da administração local em gerir políticas inter-setoriais e inovadoras; a carência de formação dos profissionais para intervir em áreas informais e gerir processos participativos, a importância da comunicação e da representação do território para o processo de planejamento juntos com os moradores. $\mathrm{Na}$ base das transformações necessárias para superar esses limites, está uma necessária mudança de prospectiva. 0 planejamento e a gestão urbana, desde o princípio, foram desenhados partindo de um lugar privilegiado e construídos na base do 'discurso competente' sobre a cidade, ou seja, na dicotomia entre o conhecimento de especialistas e usuários. A política urbana é considerada assunto de especialistas e as decisões tornam-se de natureza meramente técnica e, por isso, expressas em linguagens incompreensíveis para a maioria da sociedade. Essa atitude obviamente não valoriza as ideias e as propostas 'menores' e acaba por não valorizar, por muitas vezes, nem as críticas produzidas no próprio ambiente profissional. 0 reconhecimento da importância dos pensamentos e ideias dos cidadãos "não espertos", que guardam uma memória dos próprios lugares dispersa e geralmente não formalizada (mas por isso não menos profunda), representa a base da mudança radical que precisamos fazer para passar de uma política vertical e hierárquica para uma que aplica o princípio da democracia no seu sentido mais amplo. 
0 processo de democratização da gestão urbana encontra muitos obstáculos num momento histórico em que a cidade se tornou, mais do que nunca, uma mercadoria. Por isso a democracia tem que ser defendida e construída a partir dos lugares físicos e do acesso aos direitos a habitação, ao lugar e à cidade no sentido amplo definido por Lefebvre (1968). Nese cenário, a responsabilidade da academia é continuar a investir no processo de construção de conhecimento e de metodologias adequadas para lidar com um dos maiores desafios da sociedade contemporânea.

\section{Elena Tarsi}

Universidade de Coimbra, Centro de Estudos Sociais, Núcleo de Estudos sobre Humanidades, Migrações e Estudos para Paz.

elena_tarsi@yahoo.it

\section{Notas}

(1) Quem escreve teve a oportunidade de participar da equipe que abordou o desenvolvimento da metodologia e do plano. $O$ trabalho em estreita colaboração com os profissionais brasileiros que compunham o grupo foi crucial para o desenvolvimento das avaliações a seguir.

(2) Financiado pelo BID - Banco Interamericano de Desenvolvimento e Caixa Econômica Federal.

(3) O PDDU, atualmente em vigor, foi aprovado no 2008, Lei 7.400, de 2008.

(4) A legalização e regulamentação das condições de habitação e urbanização nestas áreas são um dos elementos-chave da política de habitação de interesse social em Salvador. As Zeis incorporaram as antigas APSEs - Áreas de Protecção Sócio-Ecológica prevista no LOUOS (Lei $n$ ㅇ 3377/84, alterada pela Lei $\mathrm{n} \cong 3853 / 88$ ).

(5) Além da Secretaria Municipal da Habitação - Sehab, organismo responsável pela produção de Política Habitacional do Município, incluir a Seplam e a Sucom, órgãos municipais de planejamento e fiscalização, Setin - Secretaria Municipal de Transportes e Infra-Estrutura e Sefaz - Secretaria Municipal da Fazenda. A Sehab desenvolvia o papel de coordenadora de todas as ações de habitação, de envolvimento de todos os órgãos da administração municipal racionalizando e potencializando as energias e as finanças. Pretende-se estabelecer articulações de cooperação técnica e institucional entre a Prefeitura de Salvador, a Secretaria de Estado da Saúde, a de Desenvolvimento Urbano Sedur e a Companhia de Desenvolvimento Urbano do Estado da Bahia - Conder, além de universidades públicas e privadas.

(6) Para uma descrição aprofundada da área veja-se Tarsi, 2014. 
(7) Um aspecto muito importante foi o envolvimento da Universidade que teve a responsabilidade de elaborar o Plano de Bairro sob a coordenação do professor Luiz Antonio de Souza, arquiteto e professor de urbanismo na UNEB. Para conduzir as atividades, foi criada uma equipe multidisciplinar, composta pelo coordenador, duas urbanistas, uma profissional de comunicação e dois sociólogos: a abordagem multidisciplinar foi fundamental a causa do carácter multissetorial do programa. Foram envolvidos inclusive alguns estudantes do curso de Urbanismo da UNEB que participaram da última parte do processo participativo e colaboraram na coletas de dados sobre uso do solo e condições das habitações.

\section{Referências}

ALFONSIN, B. e FERNANDES, E. (2003). A lei e a ilegalidade na produção do espaço urbano. Belo Horizonte, Del Rey/Lincoln Institute.

ALLEGRETTI, G. (2000). L'insegnamento di Porto Alegre: autoprogettualità come paradigma urbano. Florença, Alínea.

ALVITO, M. e ZALUAR, A. (2004). Um século de favela. Rio de Janeiro, Editora FGV.

ARANTES, O.; VAINER, C. e MARICATO E. (2000). A cidade do pensamento único. Petrópolis, Vozes.

BARTHEL, E. (2007). Un piccolo grande progetto per Torino: il piano integrato 'leggero' a San Salvario. Macramé. Torino 2005: appunti di viaggio. Florença, Firenze University Press.

BUARQUE de HOLLANDA, S. (2000). Radici del Brasile. Florença, Giunti.

DAVIS, M. (2006). Planet of Slums. Londres, Verso.

FREIRE, P. (1970). A pedagogia do oprimido. Rio de Janeiro, Paz e Terra.

FRIEDMANN, J. (2004). Empowerment. Verso il potere di tutti. Pescara, Edizioni Qualevita.

HARVEY, D. (2011). Le capitalisme contre le droit à la ville. Paris, Editions Amsterdam.

IBGE. (2010). Censo Demográfico 2010. Disponível em: http://7a12.ibge.gov.br/vamos-conhecer-obrasil/nosso-povo/caracteristicas-da-populacao.

LabHab (2003). Metodologia Consolidada para a Elaboração de Planos de Ação Habitacionais e Urbanos. Disponível em: http://www.fau.usp.br/depprojeto/labhab/biblioteca/produtos/ plano_acaohaburb_metodologia.pdf.

LEFEBVRE, H. (1968). Le Droit à la Ville. Paris, Editions Economica.

MAGALHÃES, A. (2012). Entre o legal e o extralegal. A reactualização da remoção de favela no Rio de Janeiro. Revista Brasileira de Estudos Urbanos e Regionais, v. 14, n. 1.

MAGNAGHI, A. (2005). La rappresentazione identitaria del território. Florença, Alínea.

MARICATO, E. (2001). Brasil, cidades: alternativas para crise urbana. Petrópolis, Vozes. (2010). "O Estatuto da cidade periférica". In: SANTOS CARVALHO, C. e ROSSBACH, A. (orgs.). O Estatuto da Cidade comentado. São Paulo, Ministério das Cidades, Aliança das Cidades.

MINISTÉRIO DAS CIDADES (2004). Planejamento territorial urbano e política fundiária. Brasília, Governo Federal. 
PABA, G. e PERRONE, C. (2004). Cittadinanza ativa. Florença, Alinea.

PMS (2008). Plano Diretor de Desenvolvimento Urbano do Município do Salvador. Disponível em: http://www.desenvolvimentourbano.salvador.ba.gov.br/lei7400_pddu/index.php (2014).

PMS/SEHAB (2005). Termo de Referência no 25/2005. Salvador, Sehab.

(2006). Projeto de urbanização para Produção de Lotes Urbanizados em Nova Constituinte, Memorial Descritivo. Salvador, Sehab.

QUEIROZ RIBEIRO, L. C. e ALVES DOS SANTOS, J. O. (2003). Democracia e segregação urbana: reflexões sobre a relação entre cidade e cidadania na sociedade brasileira. Eure. Santiago de Chile, v. XXIX, n. 88.

ROLNIK, R. (1999). Regulação urbanística e exclusão territorial. São Paulo, Polis.

(2003). A cidade e a lei. São Paulo, Fapesp/Studio Nobel.

(2013). Ten years of the City Statute in Brazil: from the struggle for urban reform to the World Cup cities. International Journal of Urban Sustainable Development, v. 1, pp. 1-11.

SANTOS, M. (1987). O espaço do cidadão. São Paulo, Nobel.

(1996). A urbanização brasileira. São Paulo, Hucitec.

SASSEN, S. (2010). A savage sorting of winners and losers: Contemporary versions of primitive accumulation. Globalizations, v. 7, n. 1-2, pp. 23-50.

SCLAVI, M. (2002). Aventure urbane: progettare la città con gli abitanti. Milão, Eleuthera.

TARSI, E. (2013). "Global challenges and local identity: integrated transformation of informal areas as a basis for social inclusion". In: PERRONE, C. (org.). Living Landscape for Living: Policies, Practices, Images Conference Proceedings. Florença, February-June 2012, Planum. The Journal of Urbanism, n. 27, v. II (2013), pp. 43-51.

(2014). Favelas. II Brasile della città informale tra esclusione e partecipazione. Florença, ED.IT.

TASK FORCE (2005). Una casa nella città. Migliorare le condizioni di vita degli abitanti degli slums. Roma, Cooperazione Italiana allo Sviluppo, Ministero degli affari Esteri.

TELLES, V. (2001). "Sociedade civil e a construção de espaços públicos". In: DAGNINO, E. Os anos 90: política e sociedade no Brasil. São Paulo, Brasiliense.

UNEB/SEHAB (2006). Relatório 1 - Plano de Sensibilização e Mobilização para Nova Constituinte. Salvador, Sehab.

UN-HABITAT (2008). State of the world cities 2010/2011. Bridging the urban divide. Nairobi, UNHabitat.

VILLAÇA, F. (2001). Espaço Intra-urbano no Brasil. São Paulo, Studio Nobel. (2012). Reflexões sobre as cidades brasileiras. São Paulo, Studio Nobel.

WACQUANT, L. (2007). Territorial stigmatization in the age of advanced marginality. Thesis Eleven, n. 91, pp. 66-67. Sage Publications.

Texto recebido em 30/nov/2014 Texto aprovado em 13/maio/2015 